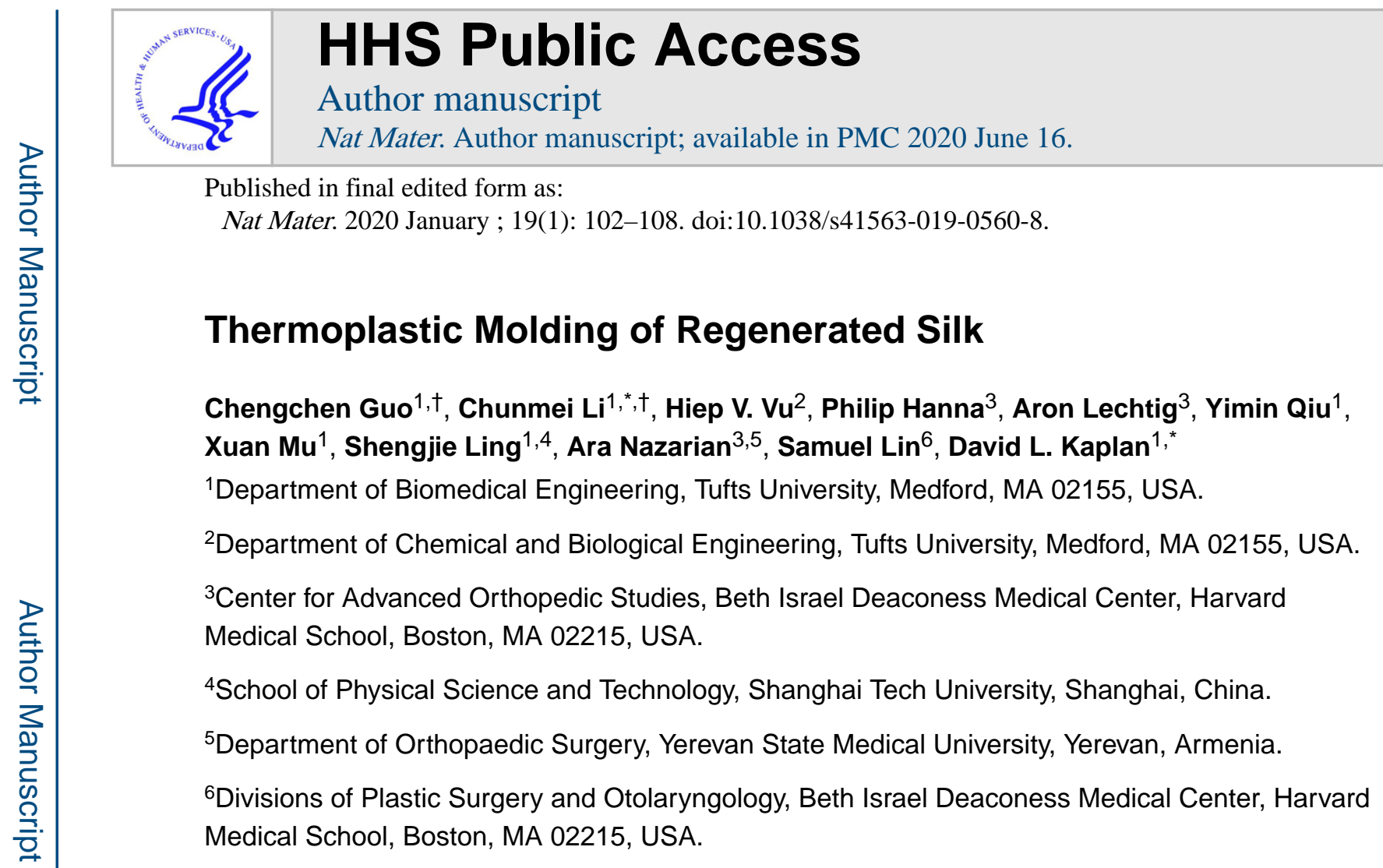

\begin{abstract}
Early insights into the unique structure and properties of native silk suggested that $\beta$-sheet nanocrystallites in silk would degrade prior to melting when subjected to thermal processing. Since then, canonical approaches for fabricating silk-based materials typically involve solutionderived processing methods, which have inherent limitations with respect to silk protein solubility, stability in solution, and time and cost efficiency. Here we report a thermal processing method for the direct solid-state molding of regenerated silk into bulk 'parts' or devices with tunable mechanical properties. At elevated temperature and pressure, regenerated amorphous silk nanomaterials with ultralow $\beta$-sheet content undergo thermal fusion via molecular rearrangement and self-assembly assisted by bound water to form a robust bulk material that retains biocompatibility, degradability and machinability. This technique reverses presumptions about the limitations of direct thermal processing of silk into a wide range of new material formats and composite materials with tailored properties and functionalities.
\end{abstract}

\footnotetext{
Users may view, print, copy, and download text and data-mine the content in such documents, for the purposes of academic research, subject always to the full Conditions of use:http://www.nature.com/authors/editorial_policies/license.html\#terms

*Correspondence to: chunmei.li@tufts.edu; david.kaplan@tufts.edu. Correspondence and requests for materials should be addressed to C.L. \& D.L.K.

${ }^{\dagger}$ These authors contributed equally to this work.

Author contributions

C.G., C.L and D.K. conceived and designed the project and experiments; C.G., C.L., H.V.V., and Y.Q. performed the materials fabrication and characterizations; P.H., A.L., and A.N. performed animal studies; C.G., C.L., X.M., S.L., and S.L. performed the data analysis and results discussion; D.L.K. supervised the entire project; and C.G. and C.L. wrote the manuscript. All authors discussed the results and commented on the manuscript.

Data availability

The authors declare that all data supporting the findings of this study are available within the paper and its Supplementary Information files and from the corresponding author upon reasonable request.

Competing interests

The authors declare no competing interests.
} 
Silk is a natural protein-based biopolymer that generally appears in fiber format with outstanding mechanical properties, useful for fabricating durable textiles and used as clinical sutures over thousands of years ${ }^{1,2}$. With the availability of modern characterization techniques, the unique properties of silks and the underlying mechanisms of protein selfassembly have been investigated ${ }^{3-10}$. This improved fundamental understanding of silk, including protein composition, molecular structures, and natural spinning mechanisms has inspired new technologies to process silk by combining chemical, biological and engineering methodologies ${ }^{1,11-15}$. Today, silk has been utilized as a material option far beyond textiles for biomaterials and scaffolds in biomedical applications, drug delivery, tissue engineering and regenerative medicine ${ }^{16-20}$.

Natural silk is a semi-crystalline biopolymer material, consisting of $\beta$-sheet nanocrystallites embedded in a less organized, less crystalline continuous phase ${ }^{21}$. The strong hydrogenbonding network in the $\beta$-sheet nanocrystallites contributes to the stability and robust mechanical properties of silks, which is the limitation in the thermal processing of silk to avoid degradation ${ }^{22-24}$. Alternatively, considerable efforts have been made toward extracting and solubilizing silk protein (fibroin) ${ }^{25-28}$, such as with concentrated $\mathrm{LiBr}$ solution used to break the hydrogen-bond network within native spun fibers ${ }^{25}$. This regenerated silk fibroin is then utilized in solution and reprocessed to generate new material formats including gels, films, sponges, fibers, and related materials ${ }^{11}$. However, these approaches require downstream processing, such as solvent removal or post curing, such as via treatment with methanol or water vapor, to generate solution-stable silk-based materials. Solvent addition and removal, with associated limits of solubility of the protein, lead to new and useful materials but at a significant cost because of various required processing steps both during and post-material formation. The limitations in material properties are due to solubility constraints and the relatively short-term stability of silk in solution due to self-assembly ${ }^{29}$.

Here, we report a new thermal processing method to transform solid-state regenerated natural silk directly into a robust structural material with tunable mechanical properties, while retaining good machinability, biocompatibility and biodegradability. The new approach with fewer processing steps, lower cost, high protein density and broader functional material options mirrors more traditional thermal processing for synthetic polymer using preformed pellets and suggests new windows of opportunity for silk processing by overcoming the current limitations associated with solution-based processing approaches. This new method involves the fabrication of 'pellets', defined here as amorphous silk nanomaterials (ASN, with diameters from $30 \mathrm{~nm}-1 \mu \mathrm{m}$ ) reconstructed from regenerated aqueous silk fibroin solution. Next, the pellets are treated by heat and pressure, leading to densification and fusion of the silk nanomaterials into bulk materials. The processed silk-based bulk materials are stronger than solution-derived materials, as well as superior when compared to most natural structural materials (e.g. wood) and to some synthetic polymers. By tuning the processing conditions, the molecular structures and physical properties of the thermal processed silk-based bulk materials can be tailored to specific ranges while retaining the good machinability to form protein-based medical devices such as bone screws and ear tubes. Furthermore, a variety of functional molecules such as enzymes and antibiotics can be incorporated into the bulk materials as dopants to make silk-based functional composite devices. 


\section{Materials characterization}

Combining top-down and bottom-up approaches to transform natural silk fibers into silkbased bulk parts via thermal processing first involves the production of ASN and then processing of ASN by hot pressing (Fig. 1a). This technique was used to directly mold silk bars, rods and plates, as well as to fabricate tubes and screws with machining (Fig. 1, b to e). Natural silk fibers from silkworm cocoons (Bombyx mori) consist of sericin and silk fibroin, a native protein $\sim 390 \mathrm{kDa}$ heavy chain and a $\sim 25 \mathrm{kDa}$ light chain ${ }^{30,31}$. By breaking the hydrogen-bond network in degummed (sericin free) natural silk fibers (Fig. 2, a to c) with concentrated salt solutions ( $\mathrm{LiBr}$ et al.), aqueous regenerated silk solutions are obtained, in a similar format to the native liquid silk in the glands (Supplementary Fig. 1 and Supplementary Table 1$)^{32}$. Fresh regenerated silk solution is then diluted, freeze-dried and milled to obtain ASN (Fig. 2, d to f). Wide-angle X-ray scattering (WAXS), Fouriertransform infrared spectroscopy (FTIR) and solid-state NMR spectroscopy showed that the silk fibroin in ASN possessed significantly different molecular structures compared to that in natural silk fibers. The nanomaterials are primarily amorphous with a low content $(<1.0 \%)$ of $\beta$-sheet structure and a high content of random coil/helical structures (Fig. 2, g to j).

Structural tailoring of the silk fibroin at the molecular level supports options to tailor the physical properties and inspires new routes for processing silk. Thermal analysis showed that the ASN had a water content of $5.0 \pm 0.5 \mathrm{wt} \%$, significantly higher than that found in degummed native silk fibers ( 2.8 $\pm 0.3 \mathrm{wt} \%$ ) (Supplementary Fig. 2a). Differential scanning calorimetry (DSC) showed that ASN had a defined water-associated glass transition $\left(\mathrm{T}_{\mathrm{g}}^{\prime}\right)$ at $65{ }^{\circ} \mathrm{C}$ and a stable glass transition temperature at $178{ }^{\circ} \mathrm{C}$ (Supplementary Fig. 2b), which agrees well with previous studies on silk films prepared by solution casting and slow drying ${ }^{33}$. A detailed stepwise scanning profile further indicated two types of bound water with ASN, weakly bound with a maximum evaporation rate at $95{ }^{\circ} \mathrm{C}$, and strongly bound with a maximum evaporation rate at $125^{\circ} \mathrm{C}$ (Supplementary Fig. 3). The bound water serves as a plasticizer, tuning the thermal properties of the silk materials. Previous studies with silk films have suggested that $\mathrm{T}_{\mathrm{g}}^{\prime}$ decreases as the residual water content increases ${ }^{34,35}$. When heating the solution-casted silk films above $\mathrm{T}_{\mathrm{g}}^{\prime}$, silk fibroin enters a viscoelastic liquid state prior to crystallization, which allows patterning, imprinting, and film welding ${ }^{36,37}$. In contrast, silk materials with a high content of $\beta$-sheet crystalline structure, such as native silk fibers, possess challenges in thermal processing before degradation occurs due to the extreme stability of $\beta$-sheet crystalline structures ${ }^{22,23}$. Recent investigations have shown that $\beta$-sheet crystalline structures can melt by fast laser heating upon input of heat energy alone, which suggests a useful way for thermally processing $\beta$-sheet enriched biomaterials but still remains challenging to be scaled up to mold bulk materials ${ }^{38}$.

\section{Thermal processing of regenerated silk}

Silk-based bulk materials were formed by direct thermal fusing the ASN at high pressure above the $\mathrm{T}_{\mathrm{g}}^{\prime}$. The ASN in powder format was first packed in a predesigned aluminum mold, followed by hot pressing at high pressure (632 MPa in this study), and densified into bulk silk plates (Fig. 3a). Increasing the temperature of hot pressing densified the silk plates with 
a visual transition from white to transparent to pale yellow, indicating thermally driven structural changes at the microscale. Cross-sectional SEM images showed that the ASN were loosely compacted at lower processing temperature $\left(25^{\circ} \mathrm{C}\right)$ (Fig. 3a, A3) and tightly compacted at elevated processing temperatures $\left(65^{\circ} \mathrm{C}\right.$ and $\left.95^{\circ} \mathrm{C}\right)$ with partial fusion (Fig. $3 \mathrm{a}, \mathrm{B} 3$ and $\mathrm{C} 3$ ). When the processing temperature reached $125^{\circ} \mathrm{C}$, the ASN were more completely fused via collapsing to smaller globules with an average size of $\sim 30 \pm 5 \mathrm{~nm}$ (Fig. 3a, D3, Supplementary Fig. 4), resulting in a similar size to the globules found in the silk solution self-assembly model ${ }^{39,40}$. At still higher processing temperatures $\left(145^{\circ} \mathrm{C}, 175^{\circ} \mathrm{C}\right)$, the nanosized silk globules further fused and underwent structural transitions to form more homogenous and fine interfaces (Fig. 3a, E3 and F3). NMR characterization of redissolved thermal processed bulk materials indicates no severe degradation occurring to the silk fibroin was detected for all processing temperatures (Supplementary Fig. 5). A combination of WAXS and FTIR characterizations identified significant $\beta$-sheet structure $(>40 \%)$ with increased crystallinity in silk plates processed at the higher temperatures $\left(145^{\circ} \mathrm{C}, 175^{\circ} \mathrm{C}\right)$, while lower amounts of $\beta$-sheet structure $(\sim 5-15 \%)$ formed when processed at lower temperatures $\left(25^{\circ} \mathrm{C}, 65^{\circ} \mathrm{C}\right.$, and $95^{\circ} \mathrm{C}$ ) (Fig. 3, b to e, Supplementary Fig. 6). In addition, WAXS revealed silk II structure (as in native silk fibers) when hot pressing was performed over $125^{\circ} \mathrm{C}$, indicating a structural transition of silk fibroin to silk II structure ( $\mathrm{q}=14.6 \mathrm{~nm}$ ${ }^{-1}, d$-spacing value of $4.3 \AA$ ) during the processing (Fig. 3 c) ${ }^{10,23}$. In combination with thermal analysis of the ASN, structural characterizations of the processed bulk silk materials provide insight into the mechanism of thermal fusing. At cold state $\left(25^{\circ} \mathrm{C}\right)$, a low level of $\beta$ sheet structure $(\sim 6.0 \pm 1.2 \%)$ was introduced by applying high pressure (shear) during the densification process (Supplementary Fig. 7). The density of the bulk material was 1.24 $\pm 0.02 \mathrm{~g} / \mathrm{cm}^{3}$, lower than the density of the natural silk fiber $\left(\sim 1.35 \mathrm{~g} / \mathrm{cm}^{3}\right)$ (Supplementary Fig. 8). Increasing the processing temperature up to the $\mathrm{T}_{\mathrm{g}}^{\prime}\left(\sim 65^{\circ} \mathrm{C}\right)$ make the density increase to $1.35 \pm 0.01 \mathrm{~g} / \mathrm{cm}^{3}$, indicating more densification due to the enhanced molecular mobility of silk fibroin chains. However, no significant $\beta$-sheet structure formation and crystallization occurred at this temperature. Increasing the processing temperature over the $\mathrm{T}_{\mathrm{g}}^{\prime}$ further enhanced the molecular mobility of the silk chains along with the water removal, facilitating thermal fusion of silk fibroin (Fig. 3f). At $125^{\circ} \mathrm{C}$, a homogeneous fused state was achieved where silk forms nano-globules via molecular rearrangement and selfassembly ${ }^{39,40}$. Notably, this is the first time that silk fibroin formation into nano-globules via self-assembly in the solid state has been observed. Further elevating the processing temperature over $125^{\circ} \mathrm{C}$ allows removal of strongly bound water and sufficient molecular mobility of silk fibroin chains to overcome the energy barrier of structural transition, forming inter- and intra-molecular $\beta$-sheets nanocrystalline structures (Fig. 3f) ${ }^{35,39}$. The presence of bound water in ASN is critical for structural transition during thermal processing. Removal of bound water from ASN by preheating results in failure of thermal molding, which however can be reversed by moisture treatment to regain bound water (Supplementary Fig. 9). The thermal processing of ASN above $\mathrm{T}_{\mathrm{g}}^{\prime}$ also allows opportunities to fabricate sophisticated silk-based devices such as screws and contact lenses directly from ASN (Supplementary Fig. 10). The accompanying structural transition to $\beta$-sheets structures at high temperatures further offers options to tune the physical properties and avoid complex post-processing treatments for silk-based devices. 


\section{Physical properties of silk-based bulk materials}

The mechanical properties of the fabricated silk-based bulk materials were characterized with three-point bending, tensile, and compression tests. Three-point bending test showed that the strength of the bulk silk materials increased with increasing processing temperature up to $145^{\circ} \mathrm{C}$ (Fig. 4, a and b). However, the strength decreased when processing at $175^{\circ} \mathrm{C}$, which is probably due to the slight thermal degradation of silk fibroin insensitive in NMR spectroscopy. Maximum strength was achieved for silk plates processed at $145^{\circ} \mathrm{C}$ with a specific strength of $109 \pm 10 \mathrm{MPa} / \mathrm{g} \mathrm{cm}^{-3}$, which exceeds some natural structural materials such as Cristaria plicata (CP) nacre and wood (Fig. 4c). A similar trend was observed for tensile and compression tests (Supplementary Fig. 11). Furthermore, lowering the processing pressure weakened the materials (Supplementary Fig. 12). In comparison to solution-based methods of fabricating silk bulk materials, this new thermal processing method produced silk materials with the best performance in compression tests (Supplementary Fig. 13) ${ }^{29,41-43}$. Besides the excellent mechanical properties, the fabricated silk-based bulk materials possessed good thermal forming properties and machinability, supporting patterning, thermal molding and machining. Figure 4d shows a DSC profile of silk materials processed at $125^{\circ} \mathrm{C}$ and $632 \mathrm{MPa}$, indicating the materials had a stable glass transition temperature of $97{ }^{\circ} \mathrm{C}$ and a crystallization temperature of $137^{\circ} \mathrm{C}$. As a result, the material became soft when heated above this glass transition temperature to allow micro/ nano-imprinting (Fig. 4e, Supplementary Fig. 14) and thermal forming to create designed constructs (Fig. 4f). Additionally, the silk-based bulk materials could be machined into rods, tubes, pins and medical devices such as bone screws and ear tubes (Supplementary Fig. 15).

\section{Tailoring properties and functions of silk-based devices}

The properties of fabricated silk-based devices including degradability and swelling property can be controlled via manipulating processing conditions. To demonstrate this point, silkbased bone screws were fabricated by machining silk bars prepared with different processing conditions $\left(95^{\circ} \mathrm{C}\right.$ and $632 \mathrm{MPa} ; 125^{\circ} \mathrm{C}$ and $632 \mathrm{MPa} ; 145^{\circ} \mathrm{C}$ and $\left.632 \mathrm{MPa}\right)$ to vary the internal molecular structure and crystallinity. The in vitro degradation profiles indicated that the degradability of the silk bone screws was tunable, where processing at $145^{\circ} \mathrm{C}$ and 632 MPa resulted in the slowest degradation rate in two enzyme solutions (protease XIV and achymotrypsin) (Fig. 5, a to c, Supplementary Fig. 16). In addition, in vitro water uptake in PBS solutions at $37{ }^{\circ} \mathrm{C}$ showed that the silk bone screws machined from silk bars prepared at $95^{\circ} \mathrm{C}$ and $125^{\circ} \mathrm{C}$ had rapid water uptake within 15 min and a maximum of $\sim 30 \mathrm{wt} \%$ (Supplementary Fig. 17). In comparison, silk bone screws machined from silk bars prepared at $145^{\circ} \mathrm{C}$ showed slower water uptake with a maximum of $\sim 20 \mathrm{wt} \%$ (Supplementary Fig. 17). These differences reflect the underlying control of molecular structure and crystallinity in silk-based devices by manipulating processing conditions. The silk bone screws showed good biocompatibility as implant devices, where they supported the formation of new bone structure on the screw surfaces without inflammation when implanted in rat femurs (Fig. 5, d to f). The lining of multinucleated, macrophage-like cells along the threads also suggests early resorption of silk at the periphery of the devices. Another appealing feature of the thermal processing is its compatibility with bioactive molecules such as enzyme and antibiotics (Supplementary Fig. 18). The enhanced thermal stability of these molecules in 
the solid state, along with the stabilizing effect of silk with biological molecules, makes it possible to integrate those molecules into the bulk material to tailor biofunctions. ${ }^{46,47}$ As shown in Fig. 5g, protease XIV-doped silk ear tubes (doping ratio is $1 \mathrm{wt} \%$ ) were successfully fabricated with thermal processing to enhance the degradability of the devices, showing great advantage over solution-based methods since protease XIV would degrade the silk fibroin in solution. Once incubated in PBS at $37{ }^{\circ} \mathrm{C}$, the protease XIV-doped silk ear tubes show faster degradation than pure silk ear tubes prepared at same condition (Fig. 5h). Furthermore, the protease XIV-doped silk ear tubes made with $145^{\circ} \mathrm{C}$ and $632 \mathrm{MPa}$ shows slower degradation than the protease XIV-doped silk ear tubes made with $125^{\circ} \mathrm{C}$ and 632 $\mathrm{MPa}$, which demonstrates the tunability of the thermal processing (Fig. 5h, Supplementary Fig. 19). The protease XIV-doped silk ear tubes made with $125^{\circ} \mathrm{C}$ and $145^{\circ} \mathrm{C}$ show residual mass ratios of $62.8 \pm 1.3 \%$ and $79.9 \pm 0.8 \%$ respectively after $72 \mathrm{~h}$ continuous incubation in PBS solutions (Fig. 5i).

\section{Outlook}

At high-pressure and elevated temperature, the free-energy change of materials (Gibbs free energy $\mathrm{G}=\mathrm{E}+\mathrm{PV}-\mathrm{TS}$ ) may allow opportunities to tune phases or molecular structures in materials, which inspired us to investigate how external factors (pressure or temperature) influence silk self-assembly in the solid state as a new silk processing strategy. Native silk fibroin self-assembles to form semi-crystalline block copolymer structures, whereby aligned $\beta$-sheet nanocrystallites provide rigidity, and an amorphous matrix promotes flexibility. Such nature-optimized stable structures challenge direct thermal processing of native silk fibroin (sericin free) with common techniques utilized in traditional polymer engineering ${ }^{48}$. The work reported here demonstrated good thermoplastic properties of regenerated amorphous silk nanomaterials, offering a time- and cost-effective way to directly process silk fibroin materials in the solid state for fabricating 3D bulk protein-based biomaterials (Supplementary Note: Cost, time and energy assessment of different techniques used to process silk into bulk materials). Comparing to native semi-crystalline silk, regenerated amorphous silk nanomaterials have a well-defined water-associated glass transition temperature at relatively low temperature, a benefit in thermal molding. The reported thermal processing method not only provides good control over structural, mechanical and degradation properties for the products and but also shows excellent compatibility with bioactive molecules. More importantly, regenerated amorphous silk was stable and can be stored over a long time period ${ }^{49}$, which circumvents limitations of solution-based processing methods to ensures reproducibility and scalability of this method.

\section{Methods}

\section{Regenerated silk fibroin preparation}

Bombyx mori (B. mori) cocoons were cut into small pieces and boiled in an aqueous $0.02 \mathrm{M}$ $\mathrm{Na}_{2} \mathrm{CO}_{3}$ (Sigma-Aldrich, St. Louis, MO) solution for $30 \mathrm{~min}$, followed by rinsing in distilled water to remove the $\mathrm{Na}_{2} \mathrm{CO}_{3}$ and sericin. The degummed silk were allowed to dry at room temperature overnight. The dried silk was dissolved in $9.3 \mathrm{M} \mathrm{LiBr}$ (Sigma-Aldrich, St. Louis, MO) solution at $60^{\circ} \mathrm{C}$ for $3-4 \mathrm{~h}$. The solution was subsequently dialyzed for 3 days in 
distilled water using Slide-a-Lyzer dialysis cassettes (MWCO 3,500, Pierce, USA). The water was changed five times during the dialysis $(1 \mathrm{~h}, 4 \mathrm{~h}, 8 \mathrm{~h}, 24 \mathrm{~h}, 48 \mathrm{~h})$. After dialysis, the solution was centrifuged for $20 \mathrm{~min}$ at $9780 \mathrm{xg}$ twice to remove insoluble impurities. The concentration of the final silk solution was determined by measuring a volume of solution and the final dried weight $(\sim 6 \mathrm{w} / \mathrm{v} \%)$. The solution was diluted and frozen using liquid nitrogen. The frozen silk solution was then lyophilized at $-80{ }^{\circ} \mathrm{C}$ and 0.006 bar until complete sublimation. The lyophilized silk was then milled into ultrafine powders using a high-speed analytical mill (20,000 rpm, 2 min, Col-Parmer), which is referred as "amorphous silk nanomaterials" (ASN). The ASN were stored in ambient dry conditions to prevent any rehydration until used in the processing steps below.

\section{Hot pressing of amorphous silk nanomaterials (ASN)}

Amorphous silk nanomaterials (ASN) was packed into predesigned mold, followed by hot pressing at $632 \mathrm{MPa}$ and variable temperatures $\left(25^{\circ} \mathrm{C}, 65^{\circ} \mathrm{C}, 95^{\circ} \mathrm{C}, 125^{\circ} \mathrm{C}, 145^{\circ} \mathrm{C}\right.$, $175^{\circ} \mathrm{C}$ ) for $15 \mathrm{~min}$. After hot pressing, the samples were cooled down to room temperature and used for characterizations. To incorporate bioactive molecules in the system, the silk powder was doped with ciprofloxacin hydrochloride (5 wt \%, Sigma-Aldrich), gentamicin sulfate (5 wt $\%$, Sigma-Aldrich), horseradish peroxidase (HRP) (1 wt $\%$, Sigma-Aldrich), and protease XIV (1 wt $\%$, Sigma-Aldrich) by thorough mixing and subject to hot processing.

\section{NMR spectroscopy}

For structural characterization of fresh regenerated silk solution, solution NMR experiments were performed on a Bruker $850 \mathrm{MHz}$ Avance IIIHD spectrometer equipped with a $5 \mathrm{~mm}$ cryogenically helium-cooled triple-resonance TCL CryoProbe. The Larmor frequency of ${ }^{1} \mathrm{H}$, ${ }^{13} \mathrm{C}$, and ${ }^{15} \mathrm{~N}$ were $850.28 \mathrm{MHz}, 213.82 \mathrm{MHz}$, and $86.17 \mathrm{MHz}$. A sealed capillary containing $\mathrm{D}_{2} \mathrm{O}$ was used for NMR locking. NOESY was performed with a mixing time of $150 \mathrm{~ms}, 11$ ppm spectral width and in both $\mathrm{t}_{1}$ and $\mathrm{t}_{2}$ dimensions, 512 and 2048 complex points in $\mathrm{t}_{1}$ and $\mathrm{t}_{2}$ dimension, 16 scans and a relaxation delay of $1 \mathrm{~s}$. TOCSY was performed with a mixing time of $60 \mathrm{~ms}, 11 \mathrm{ppm}$ spectral width and in both $\mathrm{t}_{1}$ and $\mathrm{t}_{2}$ dimensions, 512 and 2048 complex points in $\mathrm{t}_{1}$ and $\mathrm{t}_{2}$ dimension, 16 scans and a relaxation delay of $1 \mathrm{~s} .{ }^{1} \mathrm{H}-{ }^{13} \mathrm{C} \mathrm{HSQC}$ was collected with $165.8 \mathrm{ppm}$ spectra width in $\mathrm{t}_{1}$ and $11 \mathrm{ppm}$ in $\mathrm{t}_{2}$ dimensions, 256 and 1024 complex points in $\mathrm{t}_{1}$ and $\mathrm{t}_{2}, 64$ scans. ${ }^{1} \mathrm{H}^{-1}{ }^{15} \mathrm{~N}$ HSQC was collected with $28.0 \mathrm{ppm}$ spectra width in $\mathrm{t}_{1}$ and $11 \mathrm{ppm}$ in $\mathrm{t}_{2}$ dimensions, 512 and 1024 complex points in $\mathrm{t}_{1}$ and $\mathrm{t}_{2}$, 32 scans. The solid-state NMR spectra were collected on a Varian VNMRS $400 \mathrm{MHz}$ spectrometer equipped with a $3.2 \mathrm{~mm}$ triple-resonance probe operating in double-resonance $\left({ }^{1} \mathrm{H} /{ }^{13} \mathrm{C}\right)$ mode. The $\mathrm{CP}$ condition for ${ }^{1} \mathrm{H} \rightarrow{ }^{13} \mathrm{C}$ CP-MAS experiments consisted of a $2.25 \mu \mathrm{s}$ ${ }^{1} \mathrm{H} \pi / 2$ pulse, followed by a $1.0 \mathrm{~ms}$ ramped $(3 \%){ }^{1} \mathrm{H}$ spin-lock pulse of $70 \mathrm{kHz}$ radio frequency (rf) field strength. The experiments were performed with a $25 \mathrm{kHz}$ sweep width, a recycle delay of $3.0 \mathrm{~s}, 8192$ scans and a two-pulse phase-modulated (TPPM) ${ }^{1} \mathrm{H}$ decoupling level of $91 \mathrm{kHz}$ at a MAS speed of $20 \mathrm{kHz}$ for all samples. Single NMR spectrum was obtained for each sample.

For structural characterization of processed silk-based bulk materials, $30 \mathrm{mg}$ of silk-based bulk material prepared at different conditions was first solubilized in $3 \mathrm{~mL}$ of $9.3 \mathrm{M} \mathrm{LiBr}$ solution at $60{ }^{\circ} \mathrm{C}$ for overnight to achieve complete dissolution. Then the solution was then 
dialyzed using 3.5 kDa Mw cut-off Slide-A-Lyzer Cassettes (Life Technologies) against deionized water for three days with six times water change. After dialysis, the solution was centrifuged for $20 \mathrm{~min}$ at $9,000 \mathrm{rpm}$ twice to remove insoluble impurities. The concentration of the obtained silk solution was $\sim 0.35 \mathrm{wt} \%$. Then $500 \mu \mathrm{L}$ of silk solution was freeze-dried and redissolved in $600 \mu \mathrm{L} \mathrm{D} 2 \mathrm{O}$ for ${ }^{1} \mathrm{H}$ NMR characterizations. Solution ${ }^{1} \mathrm{H}$ NMR spectroscopy experiments were performed on a Bruker $500 \mathrm{MHz}$ spectrometer. ${ }^{1} \mathrm{H}$ NMR spectra were collected with a sweep width of $10000 \mathrm{~Hz}$, an acquisition time of $3.28 \mathrm{~s}$, a recycle delay of $0.5 \mathrm{~s}$, and 128 scans. Single NMR spectrum was obtained for each sample.

\section{Thermal analysis}

The thermal degradation of silk samples was measured by thermogravimetric analysis (TGA) from 30 to $800{ }^{\circ} \mathrm{C}$ in $\mathrm{N}_{2}(99.99 \%)$ with a scanning speed of $5{ }^{\circ} \mathrm{C} / \mathrm{min}$. For all measurements, samples were kept under $\mathrm{N}_{2}$ in the furnace to reach a stable weight prior to heating. Differential scanning calorimetry (DSC) measurements were carried out on a TA Instruments Q100 DSC (TA Instruments, New Castle, DE) under a dry nitrogen gas flow of $50 \mathrm{~mL} / \mathrm{min}$ with samples encapsulated in aluminum pans. Both standard DSC and temperature-modulated DSC (TMDSC) measurements were performed. In standard DSC measurements, the samples were heated from -50 to $200{ }^{\circ} \mathrm{C}$ with a heating rate of $10{ }^{\circ} \mathrm{C} /$ min. In TMDSC measurements, the samples were heated to $10^{\circ} \mathrm{C} / \mathrm{min}$ from -50 to $200{ }^{\circ} \mathrm{C}$ with a modulation period of $60 \mathrm{~s}$ and temperature amplitudes of $1.59^{\circ} \mathrm{C}$. Multiple cycles $(n>=3)$ were performed on each sample to ensure the data reproducibility.

\section{Scanning electron microscopy (SEM)}

The morphology of the scaffolds was characterized by scanning electron microscopy (SEM) (Ultra 55 field-emission scanning electron microscope, Carl Zeiss AG, Harvard University Center for Nanoscale Systems). The SEM images were collected with a voltage of $5 \mathrm{kV}$ and the samples were sputter coated with a thin layer of gold. Multiple images $(n>3)$ were taken at different spots for each sample.

\section{Fourier-transform Infrared spectroscopy (FTIR)}

Fourier-transform Infrared spectroscopy (FTIR) was carried out on a JASCO FTIR 6200 spectrometer (JASCO, Tokyo, Japan) equipped with a MIRacle attenuated total reflectance (ATR) Ge crystal cell in absorbance mode. For each measurement, the spectrum was recorded with 32 scans and a resolution of $4.0 \mathrm{~cm}^{-1}$. Multiple spectra $(\mathrm{n}>=3)$ were collected for each sample and for each experimental condition multiple samples $(n>=3)$ were made and characterized. The protein secondary structure contents were determined by performing peak deconvolution over the amide I region (1600-1700 $\mathrm{cm}^{-1}$ ) using Matlab software. The deconvolution was carried out using a secondary derivative method with four primary peaks assigned to a variety of secondary structures respectively: $1620 \mathrm{~cm}^{-1}$ ( $\beta$-sheet), $1645-1655$ $\mathrm{cm}^{-1}$ (random coil/helix), $1685 \mathrm{~cm}^{-1}$ ( $\beta$-turn), and $1698 \mathrm{~cm}^{-1}$ ( $\beta$-sheet). A Gaussian model was selected for the band shape. 


\section{Wide-angle X-ray scattering (WAXS)}

Synchrotron wide-angle X-ray scattering (WAXS) was performed on the BioCars 14BM-C beamline at the Advanced Photon Source at Argonne National Laboratory, Argonne, IL, U.S.A under the proposal GUP-61977. The wavelength of the X-ray beam was $0.979 \AA$, with a fixed energy of $12.668 \mathrm{keV}$ and the beam size on the sample was $150 \times 300 \mu \mathrm{m}$ (horizontal $\times$ vertical). Data were recorded using an ADSC Quantum- $315 \mathrm{r}$ detector. The samples-to-detector distance is $200 \mathrm{~mm}$ and beam stop is $50 \mathrm{~mm}$. An exposure time of $60 \mathrm{~s}$ was used for degummed silk fiber and ASN. For silk-based bulk materials, an exposure time of $10 \mathrm{~s}$ was used. Background measurement was performed with the sample displaced from the beam and the image was recorded under the same conditions as used with the sample in the beam. Multiple images ( $>=3$ ) were taken to get better statistics and improve on the signal/background ratio. $\mathrm{CeO}_{2}$ powder was used for instrument calibration. The 2D WAXD patterns were analyzed using the software package FIT2D.

\section{Mechanical properties test}

The three-point bending tests were carried out on an Instron 3366 machine (Instron, Norwood, USA) in flexural test mode at $25^{\circ} \mathrm{C}$ and $50 \% \mathrm{RH}$ with a loading rate of 0.2 $\mathrm{mm} / \mathrm{min}$ and $2 \mathrm{~mm} / \mathrm{min}$ for dry specimens and wet specimens, respectively. The specimens had a length of $12 \mathrm{~mm}$, width of $7 \mathrm{~mm}$ and thickness of $1 \mathrm{~mm}$. Multiple samples (>=3) were tested for each condition.

The tensile tests were carried out on an Instron 3366 machine (Instron, Norwood, USA) in tensile test mode at $25^{\circ} \mathrm{C}$ and $50 \%$ RH with a loading rate of $2 \mathrm{~mm} / \mathrm{min}$. The tested bulk silk samples were in a plate format with a length of $10 \mathrm{~mm}$ and a width of $4.3 \mathrm{~mm}$. Multiple samples ( $>=3)$ were tested for each condition. Multiple samples ( $>=3)$ were tested for each condition.

The tensile tests were carried out on an Instron 3366 machine (Instron, Norwood, USA) in compression test mode at $25{ }^{\circ} \mathrm{C}$ and $50 \% \mathrm{RH}$ with a loading rate of $1 \mathrm{~mm} / \mathrm{min}$. The tested bulk silk samples were in a rod format with a diameter of $3.0 \mathrm{~mm}$ and a height of $4.0 \mathrm{~mm}$. Multiple samples (>=3) were tested for each condition.

\section{Fabrication of silk bone screws}

Silk bone screws were machined from silk bars using a CNC lathe (Trak TRL 1440 EX, Southwestern Industries, USA). A custom single point external cutter (Vargud, USA) was used on the CNC lathe to cut screw threads by matching turning speed with horizontal speed of the cutter to cut a desired pitch length (outer diameter $\sim 1.8 \mathrm{~mm}$, pitch $600 \mu \mathrm{m}$ ). The screw heads were machined to have a cylindrical head and a slot was generated.

\section{Fabrication of silk ear tubes}

Silk ear tubes were machined from pure silk bars or silk-protease XIV (doping ratio $\sim 1 \mathrm{wt}$ $\%$ ) bars. Each ear tube has a height of $\sim 2.7 \mathrm{~mm}$ and a diameter of $\sim 3.2 \mathrm{~mm}$ for the head part. The outer and inner diameters for the tubing part are $2.0 \mathrm{~mm}$ and $1.0 \mathrm{~mm}$, respectively. 


\section{In vitro water uptake and swelling test}

Machined silk bone screws ( $\mathrm{n}=3$ per condition) were placed in $37^{\circ} \mathrm{C}$ phosphate-buffered saline (PBS) for various amounts of time ( $0 \mathrm{~min}, 15 \mathrm{~min}, 60 \mathrm{~min}, 3 \mathrm{~h}, 24 \mathrm{~h}, 48 \mathrm{~h}, 72 \mathrm{~h}, 9$ days, 15 days, and 30 days) and observed for changes in weight and diameter to signify fluid uptake and swelling. Surface moisture was removed from the sample by wiping with a Kimwipe (Kimberly- Clark, USA), the wet weight of the sample taken $\left(\mathrm{W}_{\mathrm{s}}\right)$ and the head and thread diameters were measured. The water uptake $(\%)$ was calculated.

$$
\text { Water uptake }(\%)=\left[\left(\mathrm{W}_{\mathrm{s}}-\mathrm{W}_{\mathrm{d}}\right) / \mathrm{W}_{\mathrm{s}}\right] \times 100
$$

\section{In vitro degradation test}

Machined silk bone screws ( $\mathrm{n}=3$ per condition) were incubated at $37{ }^{\circ} \mathrm{C}$ in $2 \mathrm{~mL}$ PBS solution, $2 \mathrm{~mL}$ solution of $5 \mathrm{U} / \mathrm{mL}$ protease XIV (Sigma-Aldrich, St. Louis, MO) and 40 U/mL chymotrypsin (Sigma-Aldrich, St. Louis, MO) in PBS (Sigma-Aldrich, St. Louis, $\mathrm{MO}$ ) or in PBS as a negative control. The solutions were changed every 2-3 days. At designated time points ( 2 days, 5 days, 10 days, 20 days, 30 days) groups of samples were rinsed in DI water and dried before weighing. The remaining mass of each sample was recorded, and SEM images of the samples were collected.

For in vitro degradation test of silk ear tubes, silk ear tubes ( $\mathrm{n}=3$ per condition) were incubated at $37^{\circ} \mathrm{C}$ in $300 \mu \mathrm{L}$ PBS solution. At designated time points ( 5 min, 1 hour, 3 hours, 6 hours, 24 hours, 48 hours, and 72 hours), pictures were taken. After 72 hours continuous incubation in PBS solution at $37^{\circ} \mathrm{C}$, the samples were rinsed in DI water and dried before weighing. The remaining mass of each sample was recorded and analyzed.

\section{In vivo biocompatibility test}

Machined silk bone screws were sterilized by ethylene oxide prior to implantation. The experimental protocol for animal studies was approved by the Institutional Animal Care and Use Committee of Beth Israel Deaconess Medical Center. Silk bone screws were sterilized by ethylene oxide prior to implantation. For the studies, 13-week female Sprague-Dawley rats (Charles River Laboratories International, Inc., USA) were anaesthetized with isoflurane at $5 \%$ concentration in oxygen for induction and $2.5 \%$ for maintenance. Following anesthesia, the incision area was shaved and disinfected with a povidone-iodine scrub. A lateral approach was performed via skin incision over the distal 1/3 of the femur followed by incision of superficial fascia. The intermuscular plane between the vastus lateralis and the biceps femoris muscles was separated. After proper exposure, the lateral cortex of the supracondylar region was drilled using a $1.7 \mathrm{~mm}$ drill bit, followed by the insertion of the silk screw. Muscles were then approximated using absorbable sutures (Vicryl 5-0) and skin was closed using skin clips. Buprenorphine was administered at a dosage of $1.2 \mathrm{mg} \mathrm{kg}^{-1}$ pre-op and pro re nata (as needed with visible signs of distress). The animals were designated for euthanasia at 1 month after surgery in the $\mathrm{CO}_{2}$ chamber at the animal facility of the institution. Following euthanasia, the operated femur was harvested and used for micro- CT and histology analysis. 


\section{Micro-CT analysis}

For qualitative three-dimensional (3D) evaluation, the distal metaphyseal region of femoral bones were examined by a desktop $\mu \mathrm{CT}$ system ( $\mu \mathrm{CT} 40$; Scanco Medical AG, Bruttisellen, Switzerland) using $55 \mathrm{kVp}$ peak potential, $72 \mu \mathrm{As}$ current, $250 \mathrm{~ms}$ integration time, and 30$\mu \mathrm{m}$ voxel size. $3 \mathrm{D}$ construction was done considering 200 slides ( $6 \mathrm{~mm}$ bone segment) centered on the screw shaft. Images were acquired at 50\% depth of the 3D construct in the sagittal plan to visualize the medullary canal and the screw insertion site. Images were then acquired after applying an X-ray filter to the 3D construction.

\section{Histological analysis}

The bone specimens were fixed in $10 \%$ neutral buffered formalin at room temperature for 48 h. The fixed specimens were then decalcified in EDTA for 3 to 4 weeks until the bone became flexible. Following decalcification, tissue was processed with ethanol and xylene and then embedded in paraffin on an automatic processor. Paraffin blocks of each specimen were then sectioned along the long axis of the bone and through the screw. Sections of $5 \mu \mathrm{m}$ thickness were baked on glass slides at $60{ }^{\circ} \mathrm{C}$ and then stained with hematoxylin and eosin or Masson trichrome stain.

\section{Supplementary Material}

Refer to Web version on PubMed Central for supplementary material.

\section{Acknowledgments}

This work was supported by grants from the NIH (R01AR068048, R01DE016525), the AFOSR (FA9550-17-1-0333), and the Stepping Strong Foundation, Brigham and Women's Hospital (Drs. Nazarian and Dyer). We thank Prof. Jeffery Yarger, Dr. Brian Cherry, and Nicholas Sisco at Arizona State University for help with NMR instrumentation and data collection. We thank Dr. George Dyer for clinical relevance discussions. We also thank Scott Maccorkle and Denis Dupuis at Tufts University Machine Shop for materials machining.

\section{References}

1. Vepari C \& Kaplan DL Silk as a Biomaterial. Prog Polym Sci 32, 991-1007 (2007). [PubMed: 19543442]

2. Vollrath F \& Porter D Spider silk as archetypal protein elastomer. Soft Matter 2 (2006).

3. Vollrath F \& Knight DP Liquid crystalline spinning of spider silk. Nature 410, 541-548 (2001). [PubMed: 11279484]

4. Shao ZZ \& Vollrath F Materials: Surprising strength of silkworm silk. Nature 418, 741-741 (2002). [PubMed: 12181556]

5. Jin HJ \& Kaplan DL Mechanism of silk processing in insects and spiders. Nature 424, 1057-1061 (2003). [PubMed: 12944968]

6. Askarieh $\mathrm{G}$ et al. Self-assembly of spider silk proteins is controlled by a $\mathrm{pH}$-sensitive relay. Nature 465, 236-238 (2010). [PubMed: 20463740]

7. Hagn F et al. A conserved spider silk domain acts as a molecular switch that controls fibre assembly. Nature 465, 239-242 (2010). [PubMed: 20463741]

8. Andersson M, Johansson J \& Rising A Silk Spinning in Silkworms and Spiders. Int J Mol Sci 17 (2016).

9. Yarger JL, Cherry BR \& van der Vaart A Uncovering the structure-function relationship in spider silk. Nat Rev Mater 3 (2018). 
10. Guo C et al. Structural Comparison of Various Silkworm Silks: An Insight into the StructureProperty Relationship. Biomacromolecules 19, 906-917 (2018). [PubMed: 29425447]

11. Rockwood DN et al. Materials fabrication from Bombyx mori silk fibroin. Nat Protoc 6, 16121631 (2011). [PubMed: 21959241]

12. Teule $\mathrm{F}$ et al. A protocol for the production of recombinant spider silk-like proteins for artificial fiber spinning. Nat Protoc 4, 341-355 (2009). [PubMed: 19229199]

13. Heim M, Keerl D \& Scheibel T Spider silk: from soluble protein to extraordinary fiber. Angew Chem Int Ed Engl 48, 3584-3596 (2009). [PubMed: 19212993]

14. Andersson $\mathrm{M}$ et al. Biomimetic spinning of artificial spider silk from a chimeric minispidroin. Nat Chem Biol 13, 262-264 (2017). [PubMed: 28068309]

15. Zhou Z et al. Engineering the Future of Silk Materials through Advanced Manufacturing. Adv Mater, e1706983 (2018). [PubMed: 29956397]

16. Kundu B, Rajkhowa R, Kundu SC \& Wang X Silk fibroin biomaterials for tissue regenerations. Adv Drug Deliv Rev 65, 457-470 (2013). [PubMed: 23137786]

17. Abbott RD, Kimmerling EP, Cairns DM \& Kaplan DL Silk as a Biomaterial to Support Long-Term Three-Dimensional Tissue Cultures. ACS Appl Mater Interfaces 8, 21861-21868 (2016). [PubMed: 26849288]

18. Bhattacharjee $P$ et al. Silk scaffolds in bone tissue engineering: An overview. Acta Biomater 63, 117 (2017). [PubMed: 28941652]

19. Crivelli B et al. Silk nanoparticles: from inert supports to bioactive natural carriers for drug delivery. Soft Matter 14, 546-557 (2018). [PubMed: 29327746]

20. Holland C, Numata K, Rnjak-Kovacina J \& Seib FP The Biomedical Use of Silk: Past, Present, Future. Adv Healthc Mater 8, 1800465 (2019).

21. Koh L-D et al. Structures, mechanical properties and applications of silk fibroin materials. Progress in Polymer Science 46, 86-110 (2015).

22. Pauling L \& Corey RB The Pleated Sheet, a New Layer Configuration of Polypeptide Chains. P Natl Acad Sci USA 37, 251-256 (1951).

23. Marsh RE, Corey RB \& Pauling L An Investigation of the Structure of Silk Fibroin. Biochim Biophys Acta 16, 1-34 (1955). [PubMed: 14363226]

24. Keten S, Xu Z, Ihle B \& Buehler MJ Nanoconfinement controls stiffness, strength and mechanical toughness of beta-sheet crystals in silk. Nat Mater 9, 359-367 (2010). [PubMed: 20228820]

25. Liang CX \& Hirabayashi K Influence of Solvation Temperature on the Molecular-Features and Physical-Properties of Fibroin Membrane. Polymer 33, 4388-4393 (1992).

26. Trabbic KA \& Yager P Comparative structural characterization of naturally- and synthetically-spun fibers of Bombyx mori fibroin. Macromolecules 31, 462-471 (1998).

27. Ha SW, Tonelli AE \& Hudson SM Structural studies of Bombyx mori silk fibroin during regeneration from solutions and wet fiber spinning. Biomacromolecules 6, 1722-1731 (2005). [PubMed: 15877399]

28. Cheng G, Wang X, Tao S, Xia J \& Xu S Differences in regenerated silk fibroin prepared with different solvent systems: From structures to conformational changes. Journal of Applied Polymer Science 132, 41959-41966 (2015).

29. Marelli B et al. Programming function into mechanical forms by directed assembly of silk bulk materials. Proc Natl Acad Sci U S A 114, 451-456 (2017). [PubMed: 28028213]

30. Yamaguchi K et al. Primary Structure of the Silk Fibroin Light Chain Determined by Cdna Sequencing and Peptide Analysis. J Mol Biol 210, 127-139 (1989). [PubMed: 2585514]

31. Zhou CZ et al. Silk fibroin: Structural implications of a remarkable amino acid sequence. Proteins 44, 119-122 (2001). [PubMed: 11391774]

32. Suzuki Y, Yamazaki T, Aoki A, Shindo H \& Asakura T NMR study of the structures of repeated sequences, GAGXGA (X = S, Y, V), in Bombyx mori liquid silk. Biomacromolecules 15, 104-112 (2014). [PubMed: 24266784]

33. Hu X, Kaplan D \& Cebe P Effect of water on the thermal properties of silk fibroin. Thermochimica Acta 461, 137-144 (2007). 
34. Agarwal N, Hoagland DA \& Farris RJ Effect of moisture absorption on the thermal properties of Bombyx mori silk fibroin films. Journal of Applied Polymer Science 63, 401-410 (1997).

35. Yazawa K, Ishida K, Masunaga H, Hikima T \& Numata K Influence of Water Content on the betaSheet Formation, Thermal Stability, Water Removal, and Mechanical Properties of Silk Materials. Biomacromolecules 17, 1057-1066 (2016). [PubMed: 26835719]

36. Brenckle MA et al. Protein-protein nanoimprinting of silk fibroin films. Adv Mater 25, 2409-2414 (2013). [PubMed: 23483712]

37. Brenckle MA et al. Methods and Applications of Multilayer Silk Fibroin Laminates Based on Spatially Controlled Welding in Protein Films. Advanced Functional Materials 26, 44-50 (2016).

38. Cebe P et al. Beating the heat--fast scanning melts silk beta sheet crystals. Sci Rep 3, 1130 (2013). [PubMed: 23350037]

39. Lu Q et al. Silk self-assembly mechanisms and control from thermodynamics to kinetics. Biomacromolecules 13, 826-832 (2012). [PubMed: 22320432]

40. Koebley SR et al. Silk Reconstitution Disrupts Fibroin Self-Assembly. Biomacromolecules 16, 2796-2804 (2015). [PubMed: 26284914]

41. Perrone GS et al. The use of silk-based devices for fracture fixation. Nat Commun 5, 3385 (2014). [PubMed: 24594992]

42. Li C et al. Regenerated silk materials for functionalized silk orthopedic devices by mimicking natural processing. Biomaterials 110, 24-33 (2016). [PubMed: 27697669]

43. Liu K et al. A Silk Cranial Fixation System for Neurosurgery. Advanced Healthcare Materials 7 (2018).

44. Wegst UG, Bai H, Saiz E, Tomsia AP \& Ritchie RO Bioinspired structural materials. Nat Mater 14, 23-36 (2015). [PubMed: 25344782]

45. Mao LB et al. Synthetic nacre by predesigned matrix-directed mineralization. Science 354, $107-$ 110 (2016). [PubMed: 27540008]

46. Guziewicz NA, Massetti AJ, Perez-Ramirez BJ \& Kaplan DL Mechanisms of monoclonal antibody stabilization and release from silk biomaterials. Biomaterials 34, 7766-7775 (2013). [PubMed: 23859659]

47. Li AB, Kluge JA, Guziewicz NA, Omenetto FG \& Kaplan DL Silk-based stabilization of biomacromolecules. J Control Release 219, 416-430 (2015). [PubMed: 26403801]

48. Lee JH et al. Preparation of new natural silk non-woven fabrics by using adhesion characteristics of sericin and their characterization. Int J Biol Macromol 106, 39-47 (2018). [PubMed: 28774806]

49. Kluge JA, Kahn BT, Brown JE, Omenetto FG \& Kaplan DL Optimizing Molecular Weight of Lyophilized Silk As a Shelf-Stable Source Material. ACS Biomaterials Science \& Engineering 2, 595-605 (2016). 
a

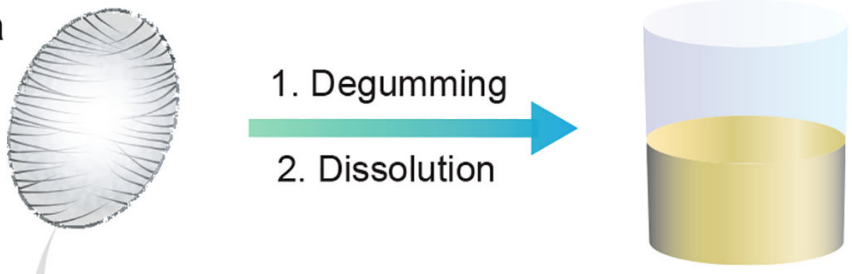

Silk fibril

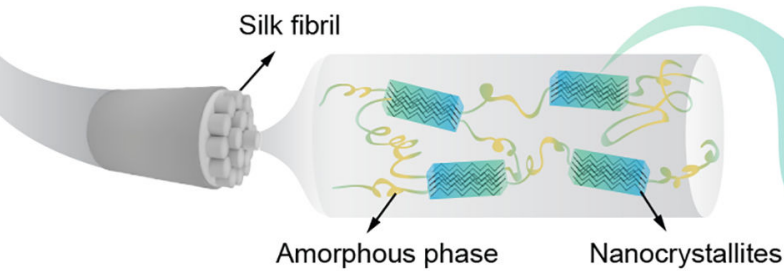

1. Freeze-drying

2. Milling

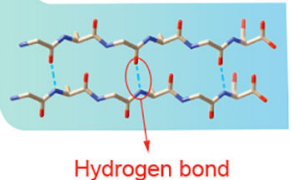

Hydrogen bond

\section{$\mathrm{N}$-terminus}

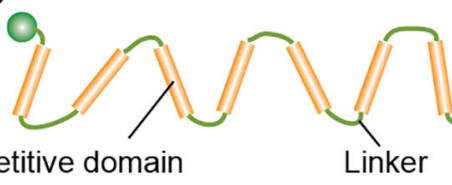

C-terminus

Repetitive domain
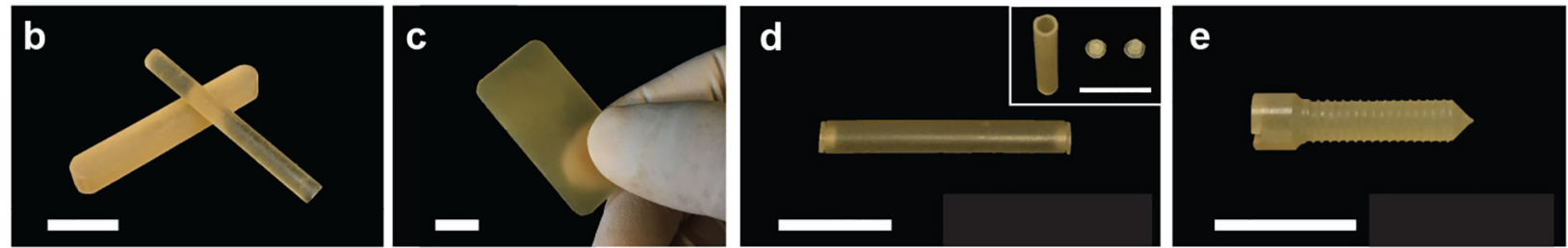

Figure 1 . Process to generate silk-based bulk materials from native silk.

a, Schematic combining top-down and bottom-up approaches to transform natural silk fibers into silk-based bulk materials by thermal processing method. Step 1, chemical treatment to dissolve natural silk fibers and generate purified silk fibroin solution; step 2, freeze-drying and milling to generate amorphous silk nanomaterials; step 3, mechanical hot-pressing with high pressure for densification, fusion and structural transition of the amorphous silk nanomaterials to semi-crystalline bulk materials. b-e, Photographs of silk bar and rod (b), plate (c), tube with caps (d), screws (e) fabricated by the thermal processing method with/ without post-machining (scale bars are $1 \mathrm{~cm}$ ). 

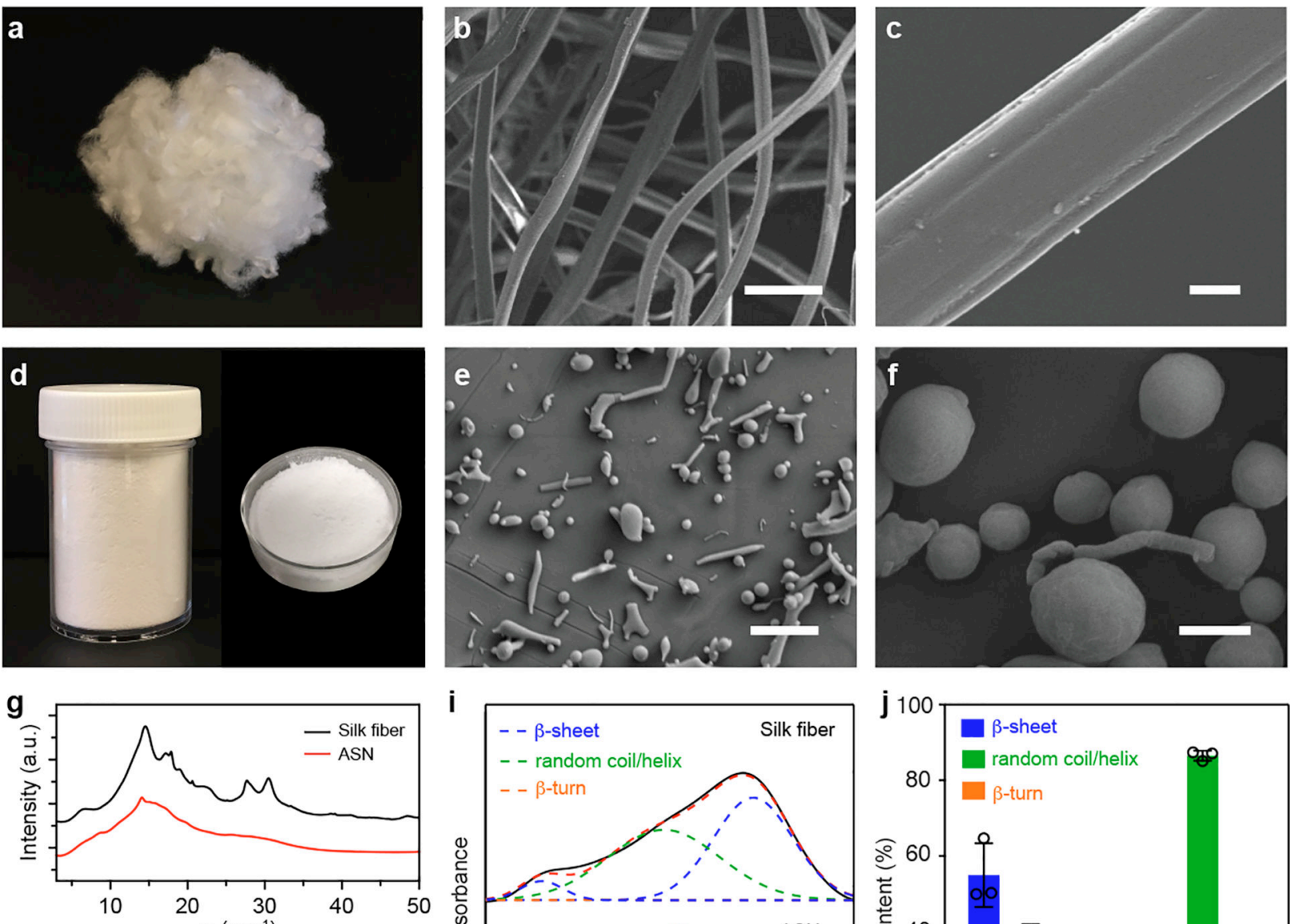

h
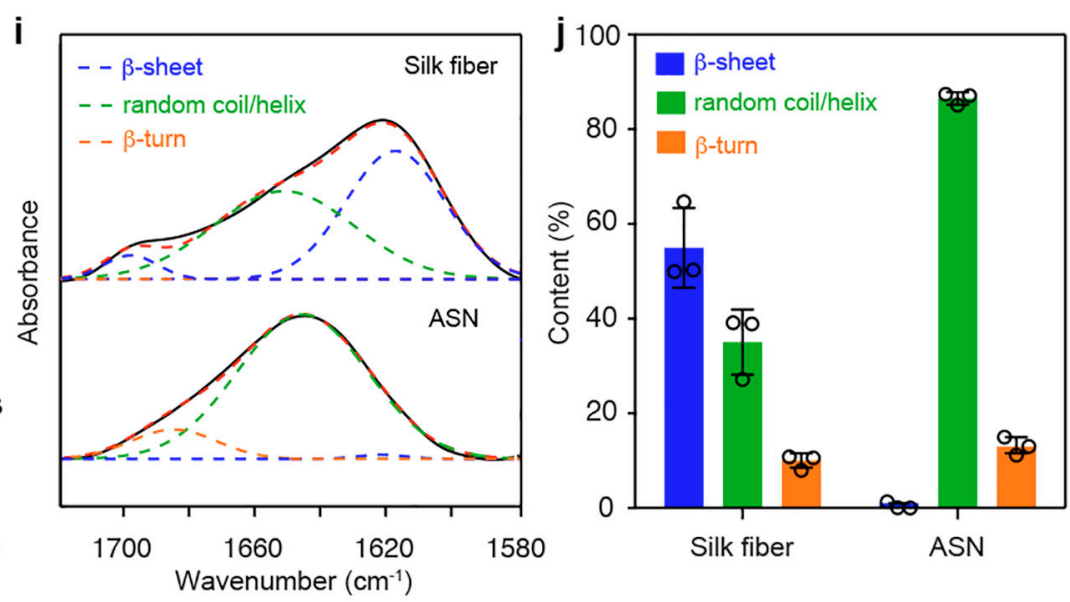

Figure 2 |. Comparison of degummed natural silk fiber and ASN.

a-c, Photograph (a) and SEM images (b, c) of degummed natural silk fibers. d-f, Photograph (d) and SEM images (e, f) of amorphous silk nanomaterials (ASN). g, 1D WAXS profiles of degummed natural silk fiber and ASN. h, Solid-state NMR spectra of degummed natural silk fiber and ASN. i, FTIR spectra of degummed natural silk fiber and ASN. j, Quantitative analysis of secondary structures present in degummed silk fiber and amorphous silk nanomaterials. Data are shown as mean \pm s.d.; $n=3$ independent experiments; the error bars represent the sample variation, measurement uncertainty, and the deconvolution uncertainty. Scale bars are $50 \mu \mathrm{m}, 5 \mu \mathrm{m}, 5 \mu \mathrm{m}$, and $500 \mathrm{~nm}$ for $\mathbf{b}, \mathbf{c}, \mathbf{e}, \mathbf{f}$, respectively. 

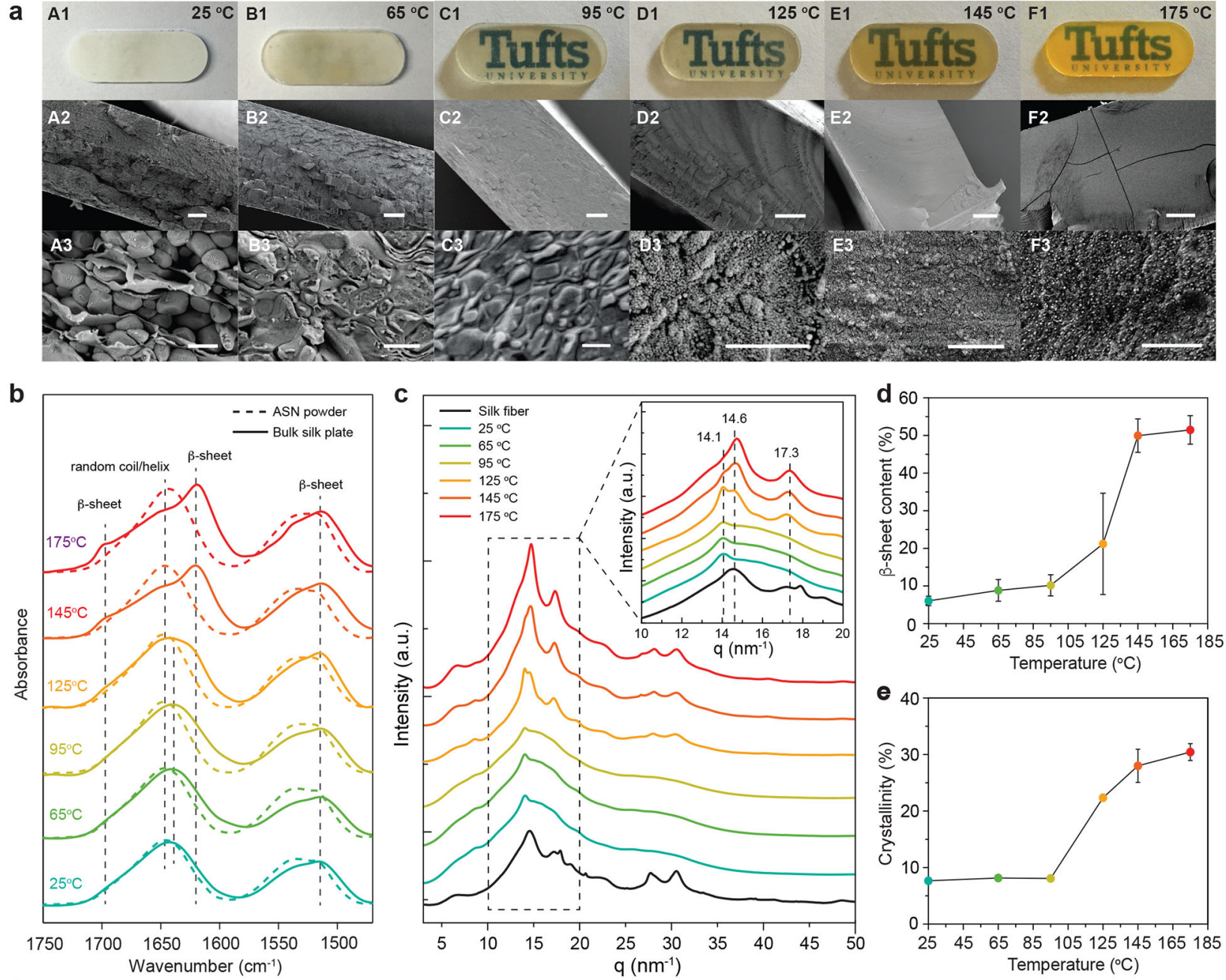

f
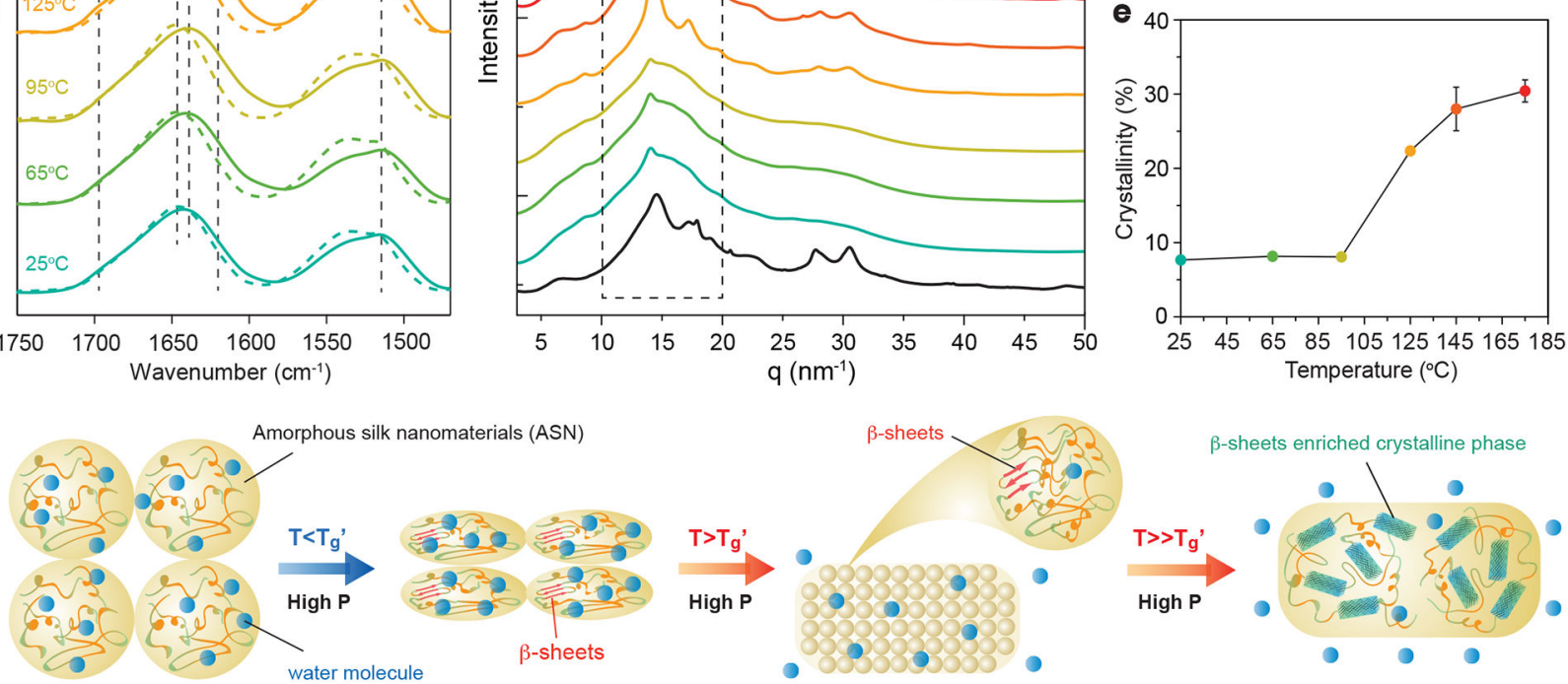

Figure 3 |. Thermal processing of ASN.

a, Photographs and cross-sectional SEM images of the silk plates prepared at different temperatures: $25^{\circ} \mathrm{C}(\mathbf{A 1}-\mathbf{A 3}), 65^{\circ} \mathrm{C}(\mathbf{B 1}-\mathbf{B 3}), 95^{\circ} \mathrm{C}(\mathbf{C 1}-\mathbf{C 3}), 125^{\circ} \mathrm{C}(\mathbf{D 1}-\mathrm{D3}), 145^{\circ} \mathrm{C}(\mathbf{E 1}-$

E3), $175^{\circ} \mathrm{C}$ (F1-F3). b, FTIR spectra of ASN powder incubated at different temperatures for 15 mins (dashed line) and bulk silk plates prepared at $632 \mathrm{MPa}$ and different temperatures (solid line). c, 1D WAXS profiles of the bulk silk plates prepared at $632 \mathrm{MPa}$ and different temperatures. Inset shows a zoom-in plot for q values from $10 \mathrm{~nm}^{-1}$ to $20 \mathrm{~nm}^{-1}$. d, $\beta$-sheet content of the silk plates quantified from FTIR spectra. Data are shown as mean \pm s.d.; $n=3$ independent experiments. e, Degree of crystallinity of bulk silk plates estimated from 1D WAXS profiles. Data are shown as mean \pm s.d.; $n=3$ independent experiments. $\mathbf{f}$, Schematic 
showing a proposed mechanism for the structural transition of ASN during thermal processing. The scales bars in (A2 to F2) and (A3 to F3) are $200 \mu \mathrm{m}$ and $1 \mu \mathrm{m}$, respectively. 

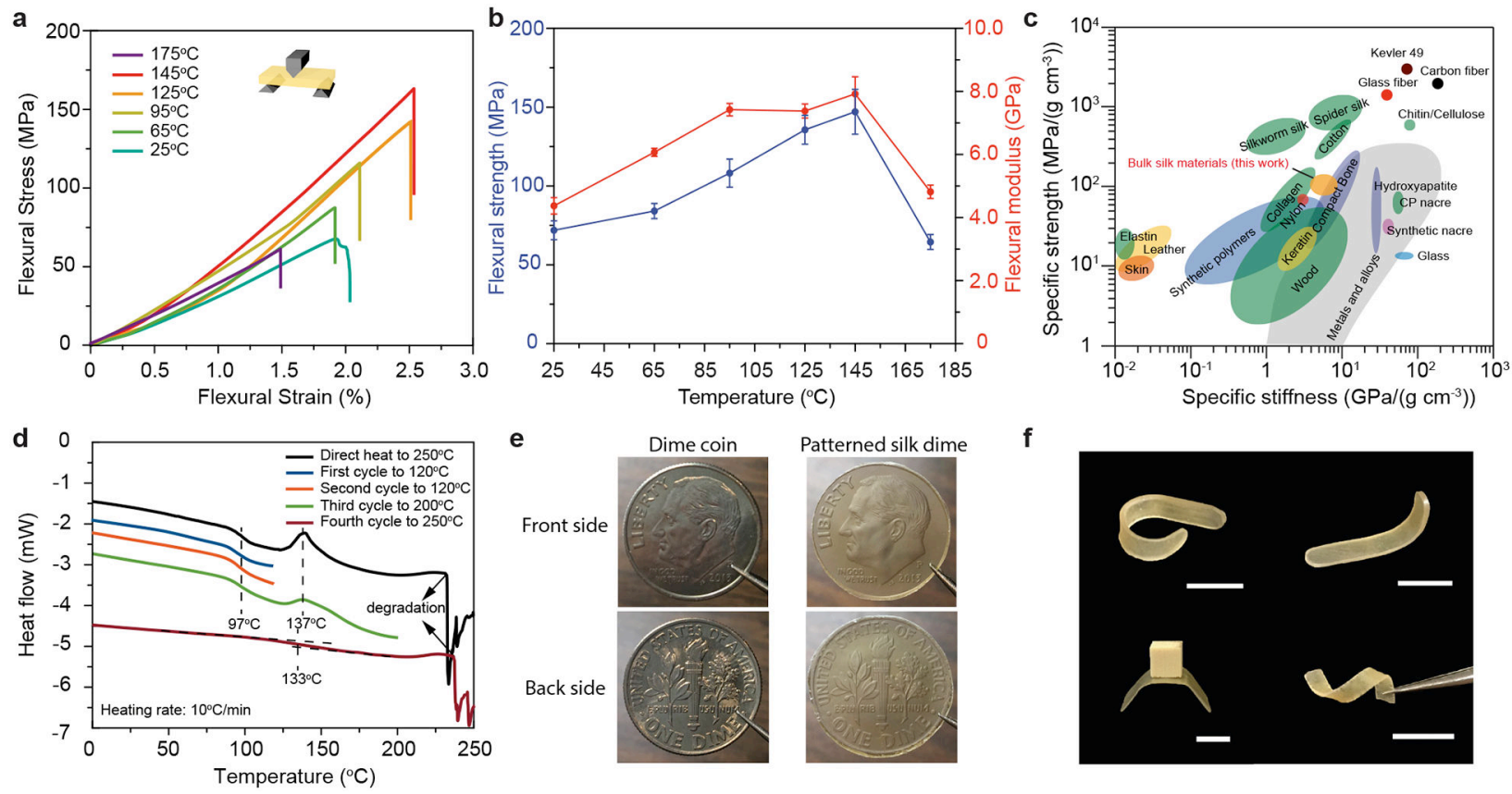

e
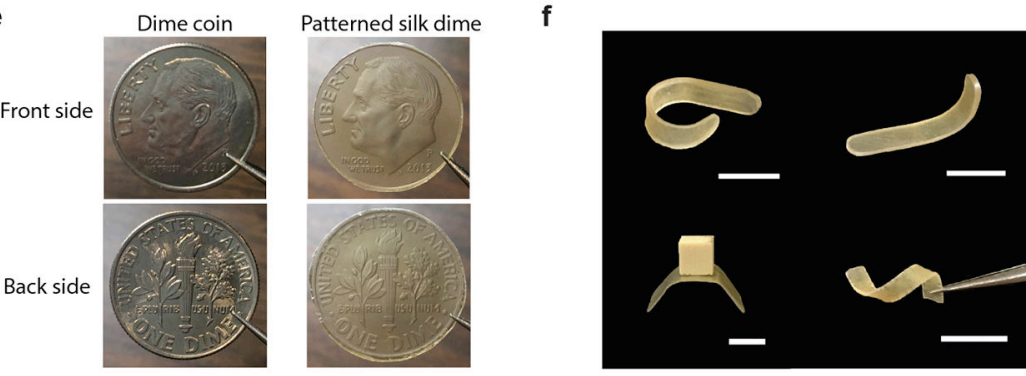

Figure 4 |. Physical properties of fabricated silk-based bulk materials.

a. Three-point bending curves for silk plates prepared at different temperatures. b. Flexural strength and modulus of the silk plates prepared at different temperatures. Data are shown as mean \pm s.d.; $n=3$ independent experiments. c. Compared with other natural and synthetic structural materials, ${ }^{44,45}$ the bulk silk materials developed in this work showed excellent mechanical properties. d. DSC curves of the silk plates prepared at $125^{\circ} \mathrm{C}$ and $632 \mathrm{MPa}$. e-f. Photographs of patterned silk dime (e) and silk structures (f) prepared by thermal forming. Scale bars in are $1 \mathrm{~cm}$. 

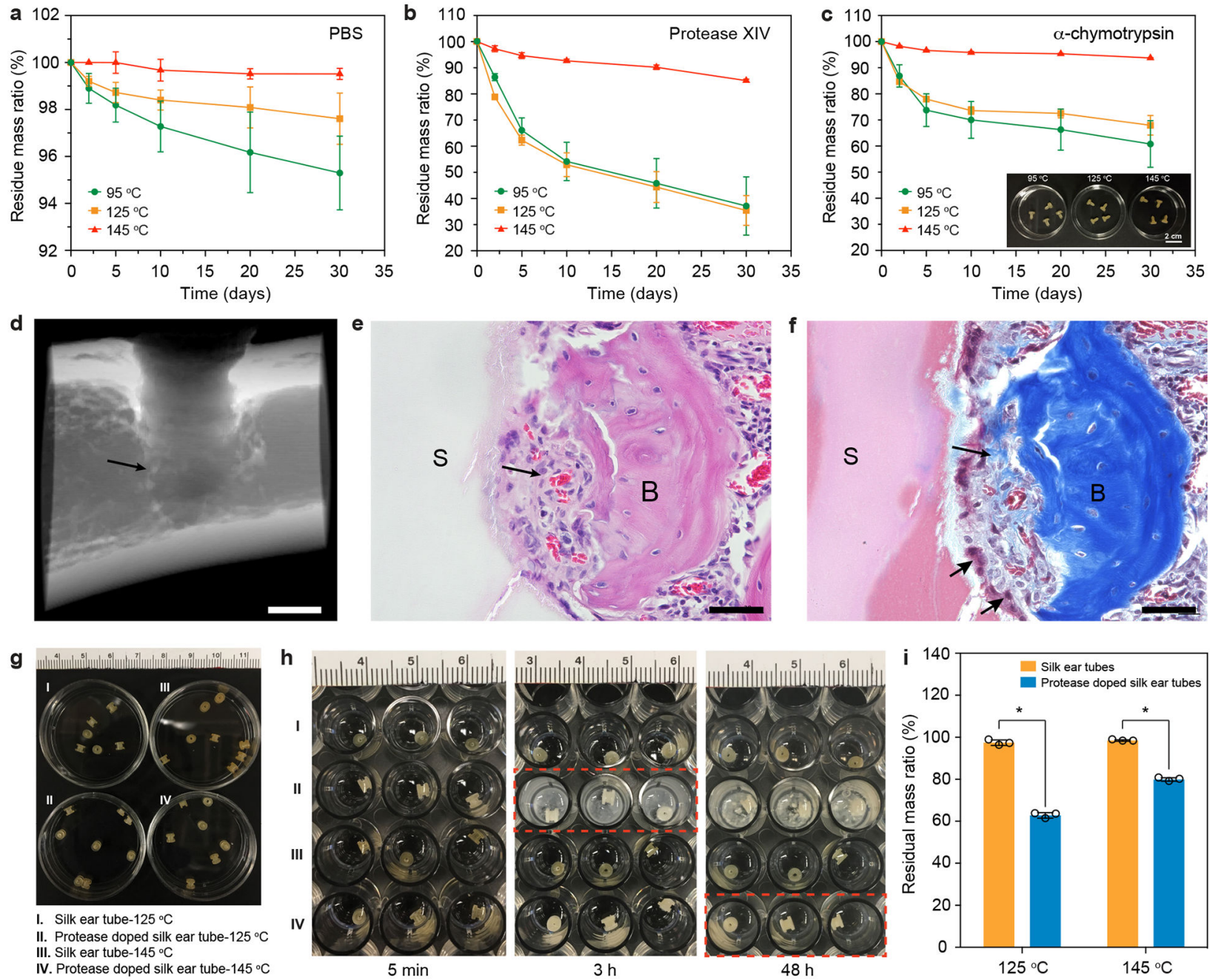

Figure $5 \mid$. In vitro and In vivo testing of functional silk-based medical devices.

a-c, In vitro degradation profiles of silk bone screws in PBS solution (a), protease XIV (5

$\mathrm{U} / \mathrm{mL}$ ) PBS solution (b), and a-chymotrypsin (40 U/mL) PBS solution (c). The silk bone screws were machined from bulk silk materials prepared at three different conditions $\left(95{ }^{\circ} \mathrm{C}\right.$, $632 \mathrm{MPa} ; 125^{\circ} \mathrm{C}, 632 \mathrm{MPa} ; 145^{\circ} \mathrm{C}, 632 \mathrm{MPa}$ ) and the photograph of as-fabricated silk screws was shown as an inset in c. Data are shown as mean \pm s.d.; $n=3$ independent experiments. d-f, In vivo testing of silk bone screw (fabricated at $145^{\circ} \mathrm{C}, 632 \mathrm{MPa}$ ) after 4 weeks implantation in rats: $\mu \mathrm{CT}(\mathbf{d})$, Hematoxylin and eosin staining (e) and Masson trichrome staining (f) demonstrated active new bone formation (long arrow) observed at the screw (S) surface along with multinucleated, macrophage-like cells (short arrow) lining the screw surface. Data are shown as mean \pm s.d.; $n=3$ independent experiments. Scale bars are 1 $\mathrm{mm}, 50 \mu \mathrm{m}$, and $50 \mu \mathrm{m}$ for $\mathbf{d}, \mathbf{e}, \mathbf{f}$, respectively. g. Photographs of fabricated silk ear tubes with or without protease XIV doping (1 wt\%). The silk ear tubes were machined from pure silk or silk-protease XIV bulk materials prepared at two different conditions $\left(125^{\circ} \mathrm{C}, 632\right.$ $\left.\mathrm{MPa} ; 145^{\circ} \mathrm{C}, 632 \mathrm{MPa}\right)$. h-i. In vitro degradation analysis of silk ear tubes with or without protease XIV doping: (h) photographs of silk ear tubes incubated in PBS at $37{ }^{\circ} \mathrm{C}$ for different times ( $5 \mathrm{~min}, 3 \mathrm{~h}$, and $48 \mathrm{~h}$ ) and (i) residual mass ratios of silk ear tubes after 
continuous incubation in PBS at $37^{\circ} \mathrm{C}$ for $72 \mathrm{~h}$. Red dashed lines in (h) indicates the observed degradation of silk ear tubes. * in (i) denotes statistically significant differences obtained from two-way ANOVA analysis, $P<0.0001$. 